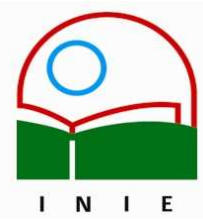

Actualidades Investigativas en Educación

Revista Electrónica publicada por el

Instituto de Investigación en Educación

Universidad de Costa Rica

ISSN 1409-4703

http://revista.inie.ucr.ac.cr

COSTA RICA

\title{
ROMPER LOS CERCOS O PERMANECER ATRINCHERADOS
}

BREAK THE WALLS OR KEEP TRENCHED

Volumen 8, Número 2

pp. $1-29$

Este número se publicó el 30 de agosto 2008

Rolando Quesada Sancho

La revista está indexada en los directorios:

LATINDEX, REDALYC, IRESIE, CLASE, DIALNET, DOAJ, E-REVIST@S,

La revista está incluida en los sitios:

REDIE, RINACE, OEI, MAESTROTECA, HUASCARAN 


\title{
ROMPER LOS CERCOS O PERMANECER ATRINCHERADOS ${ }^{\star}$ BREAK THE WALLS OR KEEP TRENCHED
}

\author{
Rolando Quesada Sancho ${ }^{1}$
}

\begin{abstract}
Resumen: La historia nos está proponiendo no solo desafíos sino imperativos en relación con los designios de la Educación Superior, y específicamente de las universidades públicas. Reclaman de ellas pertinencia con excelencia. De ahí surge la gran pregunta, ¿cómo un país subdesarrollado, con un tratado de libre comercio firmado con Estados Unidos de América, en condiciones de desventaja, puede afrontar las demandas sociales con esos referentes?

En este trabajo se discuten algunos aspectos que nos aquejan, con los cuales parte de la población universitaria no está de acuerdo, no obstante las alternativas que se proponen de manera expresa para cambiar lo establecido, no son más que acciones tímidas. De manera que partimos de aquello que se muestra como deficiencia para ir dibujando lo deseado. Este dibujo es pues, una reconstrucción desde las voces del personal académico que cotidianamente vivimos la Universidad.
\end{abstract}

Así, la problematización que se realiza y las posibles alternativas para resignificar un modelo pertinente de la Institución, no significa que sea el único, se trata tan solo de un ensayo, para mirar más allá del límite, para concienciarnos de lo dado dándose y vislumbrar lo inédito, y de esa manera llegar de nuevo a sombrarnos. En síntesis se trata de provocar la ruptura de los límites para construir la universidad del mañana.

Palabras clave: EDUCACIÓN SUPERIOR, UNIVERSIDAD PÚBLICA, MODELO ALTERNATIVO, IDENTIDAD UNIVERSITARIA.

\begin{abstract}
History is proposing us not only challenges but imperatives related to Senior Education aims, and specifically from public universities. From them is expected relevance with excellence. So here comes the great question: how an underdeveloped country, with a Free Trade Agreement signed with the United States of America, in a disadvantaged position, can face the social claims with these referrings?

In this work, some aspects that afflict us are argued, the ones which most of the university population is in disagreement with; even though the choices proposed in a expressed way to change these establishments are vague. So we begin from the aspects shown as a deficiency to foresee what is expected. This foreseen drawing is, then, a reconstruction from the academic professionals' voices that everyday live in the university environment.

In this way, the presented problematization and possible choices to remean a relevant model for the institution does not mean it is the only one; it is only a test to look beyond the limit, to bring back to conciousness and glimpse unknown things, and in that way, to astonish us again. In synthesis, it is tried to provoke the borders' breaking to build an university oriented to the future
\end{abstract}

Key words: HIGHER EDUCATION, PUBLIC UNIVERSITY, ALTERNATIVE MODEL, UNIVERSITY IDENTITY

\footnotetext{
${ }^{1}$ Doctor en Educación, Universidad Estatal a Distancia. Máster en Ciencias Sociales, FLACSO-Argentina. Director de la Escuela de Antropología e investigador del INIE.
}

Dirección electrónica: rolando.quesada@ucr.ac.cr

Artículo recibido: 5 de mayo, 2008

Aprobado: 6 de agosto, 2008

\footnotetext{
Este artículo es producto de la Investigación "Educación Pública Costarricense: Análisis Prospectivo y Desafíos de la Universidad de Costa Rica" auspiciada por el INIE, y luego tesis para optar por el título de Doctor en Educación, Universidad Estatal a Distancia.
} 


\section{INTRODUCCIÓN}

El movimiento que tiene la Universidad de Costa Rica, en términos académicos, administrativos y humanos es pocas veces perceptible en su totalidad por quienes la habitamos, tanto la población estudiantil, como la docente y la administrativa. No siempre llegamos a comprender la tramoya que sustenta el escenario donde se realiza la acción universitaria. El cuerpo actoral con su dirección, recorre ese o esos escenarios, algunos claros, otros más opacos; a veces, algunas personas actúan como protagonistas, otras como antagonistas, en fin, moviéndonos por diferentes zonas escénicas con diferentes roles, dependiendo del momento histórico en que se desarrolla la acción. Sin embargo, pocas veces percibimos las construcciones que cotidianamente elaboramos y reelaboramos en el trajín institucional.

Esto no ha permitido que los las participantes como interlocutores ${ }^{2}$ en la investigación "Educación Superior Pública Costarricense: Análisis Prospectivo y Desafíos de la Universidad de Costa Rica" externan con claridad una visión prospectiva de la Universidad, sin embargo fueron frecuentes las críticas y denuncias que le hacen al estado actual de la institución. Es en esas denuncias donde se construye la universidad deseada, esa institución que consideramos debe permanecer en este cambio de época.

Vale decir que las denuncias de la universidad no siempre corresponden a situaciones actuales sino que muchas de ellas se han configurado, desaparecido y vuelto a aparecer durante el tiempo, de manera que como se ha dicho, tienen una multitemporalidad y multicausalidad que caracterizan las construcciones de los imaginarios que sobreviven en los y las personas que integran la universidad.

Tratamos de realizar aquí, una interpretación y síntesis de aquellos aspectos que podrían estar reconfigurando la universidad deseada y por lo tanto ser parte de uno o varios escenarios y que por ende pueden ser "colocados" o distribuidos en correspondencia con las políticas de la administración central de turno.

Algunos de estos aspectos de los que dan cuenta nuestros académicos y nuestras académicas nos plantean la disyuntiva de romper los cercos o permanecer atrincherados en 
el modelo actual de universidad. Estos son los aspectos que trataremos de dilucidar y proponer en este trabajo. En primera instancia hacernos un recuento interpretativo de los discursos académicos relativos al deber ser de la Universidad, luego exponemos las tesis de Edgar Morin, acerca de los saberes que debe contemplar la Educación del futuro, para terminar con la exposición de algunos aspectos que, a nuestro juicio, debe contemplar un currículo universitario que satisfaga las inquietudes externadas por el cuerpo docente entrevistado.

\section{PREOCUPACIONES ACADÉMICAS}

\subsection{Yo la mejor de todas}

Uno de los hitos más importante en la historia de Costa Rica, fue la apertura de la Universidad, en ella confluyeron muchos intereses propios del pensamiento liberal de la época. Sin embargo, la decisión no fue un asunto que emergió en el momento en que sucedió el hecho, sino que se venía construyendo desde finales del siglo XIX y principios del XX. Estos intereses reflejados en esa decisión, hicieron de Costa Rica un país preocupado por la educación, cuestión que marcó en cierta medida, la identidad costarricense. Hombres y mujeres fueron construyendo la educación como un valor al cual todos y todas deberían tener derecho, que se consolidó como tal, luego de luchas de diferentes grupos políticos y gremiales.

Actualmente, en el imaginario universitario confluyen una variedad de posicionamientos acerca del deber ser de la educación y fundamentalmente de la educación universitaria. Las percepciones externadas reflejan cómo la Universidad "conserva, memoriza, integra, ritualiza una herencia cultural de saberes, ideas, valores [pero simultáneamente regenera esa herencia cuando la examina] al actualizarla, al transmitirla", [con lo cual se considera que es] "conservadora, regeneradora, generadora", (Morín, 2002, p. 85).

Tales percepciones no se externaron abierta y claramente, pues no todas las personas dibujaron en forma legible, la universidad deseada. Sin embargo, casi todas se refirieron en algún momento de su intervención, a aspectos que no les atraían, que rechazaban y que no tenían razón de existir, o bien sobrevaloraban algunos otros que poseían su correlato

${ }^{2}$ En esta investigación participaron como interlocutores o interlocutoras al menos 16 personas académicas que habían ocupado u ocupaban en el momento, puestos con poder de decisión. 
contrario, es decir, en aquello que se rechazaba existía un deseo y de aquello que se sobrevaloraba, se podía deducir su lado opaco, de manera que iban dibujando lo deseado y lo no deseado, para un futuro cercano. Se establece así una dialéctica entre lo que hago y lo que deseo, entre el ser y el deber ser y, es desde esta lógica que construimos la universidad que experimentamos diariamente.

No obstante, en los imaginarios podemos notar que a través del presente vamos del pasado hacia el futuro, proceso que Zemelman asume como una totalidad dada dándose.

Con claridad se identifica en términos generales, un sentimiento positivo en el cual se refleja un posicionamiento de ser la mejor universidad del país. Sentir que tiene su correlato no tan positivo, pues a partir de él se cree que la institución debe realizar pocos cambios. Este carácter conservador puede tener un referente en la necesidad de salvaguardarla y preservarla para afrontar el futuro, entonces el carácter conservador se desarrolla desde una perspectiva vital. Asimismo, se manifiesta la vertiente estéril, la cual se refleja en el dogmatismo y la rigidez, condiciones que han sido denunciadas y enunciadas por los profesores y las profesoras; es ese "valeverguismo" y "autismo" que según algunas personas han contribuido al estacionamiento académico de la Universidad, apreciación que ilustra el conservadurismo estéril, (Morín, 2002).

De manera que ser la mejor de todas, no siempre es positivo, pues en esa asunción se encierra también una actitud que podría estar inhibiendo las capacidades y oportunidades para cambiar, o retardando los cambios, y estimulando actitudes de autocomplacencia y de desidia.

Pero también considerar a la Universidad de Costa Rica, como la mejor de todas es una construcción cuyas raíces las podemos encontrar en un pasado reciente, que fue también fortalecido como arma de sobrevivencia contra la universidad privada, creando un maniqueísmo muchas veces sin fundamento. Este antagonismo y disminución valorativa de las universidades privadas y por ende sobrevaloración de las públicas y en especial de la de Costa Rica, abona en las percepciones que prevalecen en las mentes de algunos y algunas costarricenses. Dicho sentimiento tiene también su contrario pues, la sobrevaloración ha hecho que muchas personas docentes se hayan quedado en el camino, desarrollando algún tipo de autocomplacencia, que luego contribuye al afincamiento de la desidia, hoy 
negativamente señalada. Este señalamiento representa una autocrítica que con frecuencia se escucha en los pasillos y fue recurrente en las opiniones recopiladas.

\subsection{Vencer la desidia}

Asociada al sentimiento de ser la mejor de todas, ha emergido la desidia, señalada como un mal académico que se ha enraizado de tal forma que está incidiendo negativamente en la excelencia académica. La información devela que es parte del desmoronamiento del interés por reconocer y recrear el conocimiento, se deja en evidencia que se repite información y todavía se refleja una "educación bancaria", más que "aprender a aprender" y "aprender a hacer". La misión fundamental de la universidad en tanto institución educativa, es la de educar y sobre todo educar para el futuro lo cual pareciera estar en la cuerda floja. Simultáneo a esta desidia en el discurso subyace un lamento por las dificultades que hay para investigar, para compartir la experiencia vivida por académicos y académicas ya retiradas, por contratar profesionales de prestigio que visitan el país, y sobre todo la descapitalización académica, entre otros.

La desidia pareciera pertenecer a un círculo vicioso, que no nos deja ver a largo plazo; la inmediatez se convierte en seudo utopía, en el sentido de que nuestras propuestas apenas la alcanzan, en cuanto más progresa la crisis pareciera que más progresa su incapacidad para pensarla, debemos por tanto quebrar el círculo para ver al futuro, encarar el contexto y el complejo global (Morín, 2002). La desidia frena todo intento por considerar un conocimiento dado dándose, por lo contrario lleva a asumir el conocimiento dado, solamente. Lejos de enseñar la existencia de un conocimiento que no esté atravesado por el error y la ilusión, la enseñanza pareciera que se acerca más a buscar el simplismo y las verdades absolutas que permiten precisamente la repetición fácil y cómoda. Esta impronta positivista es otro de los elementos que hay que desterrar, para construir un pensamiento crítico, creativo.

La desidia se configura como una característica que hay que afrontar, pues está confabulando contra la buena marcha de la institución, estimulando no solo el estacionamiento intelectual sino el retiro de parte del cuerpo docente, quienes se asumen "cansados" de "nadar contra corriente". 
Se trata como ya se ha dicho, de no permanecer de espaldas ante el conocimiento humano, caracterizado por sus imperfecciones y tendencias al error y a la ilusión, de esa manera le damos al conocimiento su característica de cambiante, para lo cual es necesario un compromiso para crear, recrear, conocer el conocimiento dado y dándose, que se enfrenta con la desidia fortaleciendo el sentido de responsabilidad, de solidaridad, pues permite que cada uno y una se perciba inmerso en una totalidad mayor a la de su círculo inmediato, (Morín, 2002).

\subsection{Recomponer la identidad trizada}

La universidad en tanto institución crea y recrea sus propias prácticas culturales; algunos ritos, creencias, mitos, hábitos, entre otros, le son propios lo que supone que la mayoría de sus pobladores los comparten, pues ellos otorgan además de su especificidad institucional, el sentido de pertenencia. Este sentido de pertenencia se ha trizado producto de las costumbres y hábitos que han adquirido los sujetos sociales que dirigen la institución, y han presionado para que su personal comparta los espacios con otras instituciones, lo que ha ido en detrimento del desarrollo del arraigo a la Universidad. Actualmente podemos confirmar que la identidad se ha trizado, y se han creado arraigos a grupos y espacios reducidos que muchas veces no trascienden la unidad académica o más aún la carrera para la cual ofrecen cursos. Es decir, profesores y profesoras dejan de identificarse con la institución como totalidad para consolidar una identificación con un fragmento de la institución que es su núcleo laboral, eludiendo de esa forma el medio en el cual está inmersa esa instancia.

Uno de los puntos que nuclean sus percepciones es el flagelo de lo "feudal" recreado en el interior institucional, con lo cual se relacionan algunas de las debilidades identitarias. Según las creencias las unidades académicas y oficinas de las diferentes instancias administrativas, han tendido a protegerse como si fueran pequeños núcleos aislados, actuando en algunas ocasiones como pequeñas universidades, creando con ello un sentido de pertenencia acotado, solo con aquellos bienes materiales y simbólicos propios de la unidad para la cual trabajan. Romper los cercos y abrir los feudos académicos parece ser la opción deseada que se teje detrás de estas denuncias, de una parte del personal universitario, por lo cual debemos recomponer la identidad universitaria sin fragmentaciones, y aprender a convivir y estar, tanto en la institución como en ámbitos más amplios. Es decir aprender a vivir, a compartir, a comunicarse, a comulgar. En definitiva desde la Universidad debemos aprender a desarrollar el sentido de pertenencia a la cultura académica, compuesta por la 
multidisciplinariedad e interdisciplinariedad, por la interculturalidad y no como cercos pertenecientes a espacios reducidos, sino perteneciendo y definiéndose en relación con el "otro", tanto disciplinar, como étnico, es decir hacer de la diferencia una característica universitaria, del país, del Planeta Tierra, para lo cual debemos apropiarnos de la conciencia antropológica, ecológica, cívica terrenal y espiritual.

Evitar la fragmentación identitaria significa no encapsularnos en los conocimientos específicos, por lo contrario nos lleva a crear una exogamia académica y abrir los cercos a los problemas globales, para lograr con ello una lectura pertinente de los problemas. Así el pensamiento vinculante reemplaza la causalidad unilineal y unidireccional por una muliticausalidad multirreferencial lo que permitirá aprehender nociones simultáneamente complementarias y antagónicas (Morín, 2002).

La identidad no se triza por casualidad, sino que muchas veces son las propias condiciones de existencia las que lo provocan. Tal como se ha comentado, el "camaroneo" y los nombramientos interinos, impiden al profesorado, en cierta medida, la permanencia en una sola institución, fragmentando así las responsabilidades y su identificación. El reto es lograr una planilla de profesores que se dediquen tiempo completo a la Universidad con un salario digno, esto podría retener a quienes se pensionan sin desearlo objetivamente y evitar la descapitalización académica. Recordemos también que los profesores y las profesoras interinas no participan de las actividades propias de la unidad académica para la que laboran, contrariamente, su compromiso es ofrecer el curso y las actividades propias de él solamente.

El fortalecimiento identitario es un factor imprescindible para configurar la educación universitaria con un currículo pertinente, de manera que la identidad como ser humano e institucional articulado a la identidad planetaria, se presenta como basamento para esa pertinencia de la Universidad en tanto institución pública. Como puede deducirse la identidad trizada incide como obstáculo para lograr una educación con excelencia, amén de coadyuvar al encapsulamiento y fortalecimiento de la enseñanza disciplinar en detrimento de la excelencia académica. Buscar la identidad universitaria, no significa ampliar el cerco, se trata de romperlo como se ha dicho, para ubicarnos como pertenecientes también a ámbitos más amplios que nos ayuden a solucionar problemas en forma inclusiva y construir la identidad terrestre. Hay que aprender a estar ahí, lo que significa "aprender a vivir, a compartir, a 
comunicarse, a comulgar: es aquello que sólo aprendemos en y por las culturas singulares" Morín (2001, p. 73).

\subsection{El regreso a la interdisciplinariedad}

Los esfuerzos realizados en la Institución por crear un currículo con una perspectiva interdisciplinar, pareciera que se disiparon con el tiempo. Sin embargo en los imaginarios anida la construcción de que el conocimiento disciplinar se agotó para comprender la naturaleza humana. De ahí que hoy se ha vuelto la mirada hacia la comprensión de lo complejo, de lo humano, no con simpleza sino con perplejidad, pues el reservorio de conocimientos que se tenía, no era suficiente. Pensar en lo interdisciplinar como enfoque curricular supone destronar al positivismo de su poder y desterritorializarlo. El positivismo ha atravesado la organización de las y los sujetos sociales, y la ha separado en tractos económicos, sociales, culturales, políticos, educativos, entre otros, promoviendo una visión de mundo fragmentada y reduccionista, no permitiendo el conocimiento de la naturaleza humana en forma holística, distorsionando las aproximaciones de las realidades.

Lo disciplinar es una categoría que venimos arrastrando de la modernidad, la cual permitió organizar el pensamiento científico y ha instituido la división y la especialización del trabajo, por más que esté "inserta en un conjunto científico más vasto, una disciplina tiende, naturalmente, a la autonomía, por medio de la delimitación de sus fronteras" (Morín, 2002, p.115). Así, un cerco o una disciplina se caracterizan, mediante el lenguaje, por las técnicas que crea y utiliza y hasta por las teorías. Esto es lo que una parte del cuerpo docente desea conservar, con lo cual abona al mantenimiento de una universidad que remoza de alguna manera el modelo mapoléonico y la aleja de la pertinencia. La interdisciplinariedad abandonada o resignificada, de manera temprana, se convierte entonces en una posibilidad que se debe retomar como un saber necesario si queremos que la universidad pública prevalezca con pertinencia en una sociedad inmersa en la ola globalizadora. La interdisciplinariedad nos ofrece la posibilidad de comprensión de nosotros, seres humanos, pendulando entre la unidad y la diversidad en todos los campos.

\subsection{La perspectiva humanista}

La perspectiva humanista ha sido identificada con claridad, por los y las estudiantes como una característica de la Universidad, pero es recurrente por parte del sector docente que su conceptuación se ha venido desvirtuando. Para ser coherentes y consecuentes con lo 
anotado, los nuevos escenarios de la Universidad, deben contemplar las humanidades como una perspectiva fundamental que nuclee los procesos de enseñanza. El componente humanista es indispensable para estrechar la relación entre la Universidad y la sociedad, dado que la verdadera comprensión de las diferencias e intersubjetividades nos faculta para aproximarnos en forma asertiva al otro. Esta condición es básica para la creación de una conciencia lúcida que nos permita la transformación no solo individual sino colectiva.

El componente humanista debe también remozarse y resignificarse a la luz de los avatares actuales, con el fin de sustentar nuevas miradas a las realidades sociales, para estrechar la relación entre la Universidad y la sociedad, y mirarnos como ciudadanos planetarios. En esa medida no puede dejarse de lado una ética, que nos provea de elementos para comprendernos no como entes abstractos sino como personas vitales amenazadas de muerte. Así construir esta noción ética de seres humanos debe conducirnos a autocontroles en convivencia democrática y respetar la comunidad planetaria. No debemos olvidar que las humanidades estimulan la reflexión sobre el saber y favorecen la integración personal de los conocimientos, por tanto dado que, desde la cultura científica se inhibe en gran medida, la aproximación a la cultura de las humanidades, ésta debe integrarse para que todas las formaciones la tengan como componente, y se puedan nutrir acerca de los problemas generales globales, ya que "el mundo técnico y científico ve solo como ornamento o lujo estético la cultura de las humanidades" (Morín, 2002, pp. 18-19).

\subsection{El corsé administrativo}

La necesidad de una universidad ágil, menos administrativista y burocrática es una premisa que casi en su mayoría manifestaron las personas. No obstante, esto no quiere decir que toda la estructura se debe transformar, pues en principio sostienen que ella está bien y funciona. Sin embargo discuten algunos hechos puntuales que lejos de suprimirlos deben ser revalorados para que sus resultados sean pertinentes con el momento histórico. Así los congresos universitarios, contrario a la opinión de muchas personas acerca de que no funcionan, hay quienes sostienen que no se deben realizar por obligatoriedad sino por necesidad, "siempre y cuando estén las condiciones dadas", sin someterse a lo descrito en el Estatuto Orgánico, que cual indica que deben realizarse al menos cada diez años. Esto haría del congreso una instancia de discusión y toma de decisiones ágil. Se enfatiza así la importancia de realizar los congresos, pero antes debe ser revisada la normativa vigente para su correcta ejecución. 
Otras dependencias universitarias deben ser remozadas y reestructuradas para que recuperen el espíritu que sustentó su creación. Este es el caso de las Vicerrectorías y del Consejo Universitario, que según el imaginario se han convertido en complejas instancias de poder y se han alejado de los propósitos fundacionales. Asimismo otras, hay que "desburocratizarlas", como la Oficina de Administración Financiera, Oficina de Servicios Generales, Recursos Humanos, para que respondan a las necesidades universitarias y fundamentalmente a las actividades académicas, pues en la actualidad sus rutas están a contramano y no favorecen ni la investigación, ni la docencia y ni la acción social. La interrelación negada que hay entre ellas se acentúa si no se reestructuran. Esto nos lleva a pensar en un modelo administrativo diferente al actual, que estaría revolucionando las formas de implementar algunos procedimientos y procesos que la tradición se ha encargado de consolidar y convertirlos en estructuras rígidas que nadie quiere tocar. "Se puede señalar que el soporte administrativo de la academia falla e incide en la calidad con que se llevan a cabo las acciones sustantivas, cuya efectividad está determinada por la pertinencia de este servicio y elementos de apoyo" (López, 2004, p. 123).

La creación de una instancia que actúe como contraloría académica es una necesidad compartida, de ahí que la preocupación es romper las ataduras administrativas para agilizar los procesos académicos, pero a su vez crear una instancia que permita implementar un orden en correspondencia con las nuevas normativas. Esto a su vez flexibilizaría los currículos y crearía instancias que apoyen la labor docente. Es en ese sentido que se puede avanzar en el regreso a la interdisciplinariedad en forma asertiva, para que el conocimiento se vea también favorecido. Asimismo una reestructuración curricular debería procurar la incorporación de nuevas tecnologías en la formación de los y las estudiantes, previa capacitación del profesorado, lo cual es resorte de la administración, en tanto que implica no solo presupuesto, sino decisiones para su consecución. Es de esa manera que la universidad se permitiría inocular en la sociedad una práctica cultural que ayude a los ciudadanos a vivir su destino, pero también tiene que "adaptarse a las necesidades de la sociedad contemporánea y llevar a cabo su misión de conservación, transmisión, enriquecimiento de un patrimonio cultural' (Morín, 2002, p. 87), lo que nos diferenciaría de las máquinas. 


\subsection{El currículo esperado}

Concienciarnos de que debemos realizar cambios para seguir siendo pertinentes en un cambio de época, no basta con una formación disciplinar. La comprensión de la identidad compleja del ser humano para aproximarnos a las realidades, nos lleva a pensar en un currículo diferente, en procesos de enseñanza y aprendizaje en los cuales deben confluir varias temáticas disciplinares, así nos aproximamos a la comprensión de la unidad y la diversidad como característica propia del ser humano. En otras palabras estamos proponiendo que el currículo de un futuro cercano debe pensarse desde una perspectiva interdisciplinaria, lo que nos obliga a enfrentarnos a un cambio, que significa vencer de alguna manera la desidia que caracteriza la acción académica actual. Asimismo cambiar y estar cambiando significa también una permanente exposición a la incertidumbre, lo cual más allá de aprender y aprehender como profesionales se trata también se trata de enseñar como docentes, enfrentar los riesgos, lo inesperado y lo incierto, para aportar con base en los conocimientos adquiridos para ello.

Pensar lo curricular de esta manera también obliga a reestructurar el andamiaje administrativo. La administración, esa entidad sobrecargada de normas y procedimientos, percibida como un corsé que oprime a la gorda, y no la deja accionar. Soltarle el corsé a la gorda, para que se acomode a las circunstancias en conjunto con nuevas lecturas de la sociedad, debe resultar en una instancia ágil y flexible acorde con una visión diferente de universidad diferente.

De esa forma podemos pensar que la formación interdisciplinaria está asociada con una responsabilidad académica y por supuesto una identidad y compromiso por parte del cuerpo docente, y como veremos de un apoyo administrativo. Esto es relevante en la medida en que asumamos también el cambio de época como un cambio en todos los órdenes, desde la comprensión de la naturaleza del ser humano y su relación con el planeta Tierra. De ser así la interdisciplinariedad, el vencimiento de la desidia y la formación de una identidad académica se convierten en una posibilidad de ofrecer una formación pertinente. Resurge entre los intersticios de los componentes de los escenarios futuros, la ética del género humano, condición para establecer nuevas formas de relacionarnos con nosotros mismos y con el otro, y para buscar la autonomía individual y comunitaria (Morín, 2004). 
Un cambio curricular debe ir acompañado de un cambio administrativo esto por cuanto la administración debe procurar ser fundamentalmente un apoyo y no un obstáculo a la docencia. La interdisciplinariedad, que posee un sustento curricular más que administrativo, ha sido abandonada según los interlocutores y las interlocutoras por cuestiones administrativas, luego por supuesto no se descartan las ideológicas y políticas, de modo que se necesita un cambio o mayor flexibilidad en las instancias que regulan la distribución de las cargas académicas y desde las unidades académicas que administran el currículo. Las implicaciones sí o sí, representan una reforma que alcanzaría todas las esferas universitarias, con lo que queremos decir que se trataría de una nueva concepción de universidad. En ese sentido la propuesta de una educación continua no puede desligarse de la noción de reforma, pues ello implica una nueva epistemología y ontología, dado que las concepciones de realidad y las relaciones con ella, se verían resignificadas.

\subsection{El cambio que se avecina}

El cambio de época nos está empujando a la reconfiguración social y cultural, para la cual no siempre estamos preparados. No podemos dejar de reafirmar que si queremos una universidad socialmente pertinente, debemos pensar no solo la construcción del conocimiento desde otro lugar, sino que la institución reconfigurada, que asista a esa reconstrucción y no la detenga. Esto obliga a transformaciones curriculares profundas, donde la formación profesional no sea disciplinar, como se anotó, sino con base en currículos flexibles en los cuales confluyan saberes de diferentes áreas del conocimiento coadyuvando para la solución de problemas en forma holística. Desde esta perspectiva podemos anotar que la incorporación de tecnología de punta es inminente así como nuevos contenidos, los cuales deben asombrar y conducir a cambios de pensamiento, y democratización de los accesos al conocimiento, se expresa como inquietud en algunos y algunas docentes. Estas inquietudes llevan implícita la pregunta ¿cómo sobrevivir y competir con los massmedios que se entronizan en los hogares y revolucionan las formas de pensar de sus usuarios? La educación universitaria debe entonces buscar nuevas formas, que logren que estudiantes y profesores se interesen por los procesos de enseñanza y aprendizaje, buscando opciones donde la tecnología sea un vehículo útil y accesible.

Si una de las tareas de la Universidad es precisamente ser el vehículo para generar y comunicar el conocimiento, debemos prestar atención y crear un andamiaje tanto administrativo como académico, ágil y asertivo que permita transformar el conocimiento en 
un factor democrático que favorezca a la sociedad en general. Por otro lado, incentivar prácticas culturales que nos lleven a fortalecer la cultura académica, es otro reto que la investigación, articulada en forma real a la docencia puede coadyuvar a incentivar al cuerpo docente, en tanto sujetos hacedores de esa cultura, abandonen la desidia. Así, se debe procurar abandonar las creencias y los dogmas ideológicos y teóricos, y revisitarlos para releerlos a la luz de las realidades, solo de esa manera podemos precisar una universidad pertinente. Pareciera entonces que debemos reconocer en el texto, la complejidad del contexto planetario, para lo cual debemos realizar ajustes y reformas en el pensamiento, que nos permita leer la realidad de manera holística y no en forma fragmentada y compartimentada.

La educación continua es una posibilidad para responder a los cambios de época, lo que permitirá procurar el conocimiento sobre el conocimiento, para producir más conocimiento, (De Souza, 2001), lo cual debe realizarse sobre la base de la investigación interdisciplinaria y de cara a las necesidades sociales. De esta manera la pertinencia de la universidad pública pareciera asegurarse, lo cual a su vez reclama una reforma curricular, que da por descontado la reforma en todos los ámbitos académicos. Esto también supone incorporar nuevas modalidades que incluyan la educación a distancia, que fue anotada como posibilidad por parte del cuerpo docente. La educación a distancia involucra otros elementos analizados como las nuevas tecnologías y los cambios curriculares y administrativos, de modo que en su conjunto se presentan como urgencia.

Pero la urgencia de una reforma no va a surgir por sus propios recursos, es a partir de la discusión y reflexión crítica que puede instalarse en las mentes de quienes habitamos la academia. "Despejar los grandes interrogantes sobre nuestra posibilidad de conocer", dice Morín (2001), es lo que pareciera está trazando nuestra ruta, pero de modo paulatino, esa urgencia de una reforma también viene a nuestro encuentro. Comprender y asumir el cambio de época debe llevarnos a mover las estructuras sobre las cuales está fundada la universidad actual, muchas de ellas heredadas del Medioevo.

\section{ELEMENTOS PARA CONSTRTUIR UN ESCENARIO}

Las preocupaciones que hemos discutido, llevan a buscar sustentos teóricos que nos aproximen a una relectura para elaborar una propuesta. Hemos retomado de Edgar Morin, algunas tesis que nos permitirán luego concatenar las preocupaciones docentes con las 
posibilidades de la Universidad de Costa Rica para implementar un currículo alternativo. Esto por cuanto la globalización está enmarcando un modelo de universidad que la aleja de sus fines y principios.

La orientación que está tomando la universidad es la de obtener mejores resultados con menor financiamiento, lo que obliga al autofinanciamiento indiscriminado, asimismo se encuentra en una carrera por convertirse en una institución competitiva en el ámbito internacional dentro del mundo tecnológico, productivo, financiero y comercial, obviando en la mayoría de las veces el componente social, cultural y la política propia (Juárez, 2002).

El autor citado nos dice que

No es que se esté en contra de la tecnología al servicio de la educación, de ninguna manera, pero pregonar que únicamente el uso de la tecnología garantiza una educación de calidad, es confundir el acceso a la información con la formación para discernir esa información, pues, cualquiera puede acceder a cualquier información sobre cualquier informe, en cualquier portal y de cualquier forma que se presente en Internet; sin embargo, no cualquiera es capaz de analizarla, filtrarla, discernirla, valorarla y servirse de ella para su adecuada formación humana, científica, tecnológica, política. (Juárez y Comboni, 2002, p. 20)

De ahí que se puede pensar que en la actualidad exista la tendencia a disminuir la matrícula en carreras del área social y se incrementen en aquellas del área de ingenierías y las que de alguna manera están ligadas a la producción y a las tecnologías de punta, a pesar de que las carreras del área social son las que tienen ingreso libre.

En consecuencia la vida cotidiana de la universidad ha variado sustancialmente, los valores y los principios que la sustentaron, se han resignificado en función de las orientaciones empresariales (se instala así la perspectiva técnico-productiva) (París, 2002).

Didrickson (2002) dice que las profesiones tradicionales liberales, aquellas dirigidas a un mercado unidimensional están en crisis, y pone sobre el tapete el perfil de egreso, el tipo de carreras, la disciplinariedad cerrada, diferenciada, como escenarios que limitan y hasta inhiben las posibilidades de crear nuevo conocimiento. 
No hay duda de que existe la preocupación por ofrecer una formación que permita a los graduados y graduadas, participar de la vida productiva del país en forma crítica. Para ello, según se puede leer de los autores citados, se hace urgente flexibilizar las formaciones de manera que quien ingrese en la Universidad, tenga acceso a la disciplina que desea desde otro escenario.

En esa línea otros autores como Morín (1999), han elaborado algunas tesis que provocan la discusión, esa al menos parece ser el documento que el autor trabajó para la UNESCO. En él expresa que la educación del futuro debe contemplar al menos siete saberes calificados como necesarios, ellos son: "las cegueras del conocimiento: el error y la ilusión; los principios de un conocimiento pertinente; enseñar la condición humana; enseñar la identidad terrenal; enfrentar las incertidumbres; enseñar la comprensión; la ética del género humano".

Al referirse al primer saber, el error y la ilusión dice que la educación no debe permanecer ciega ante lo que es el conocimiento humano, dado que ella es la que comunica el conocimiento. Esto sin perder de vista que el mismo conocimiento humano está caracterizado por sus imperfecciones y por sus tendencias al error y a la ilusión. Esa antinomia es la que promueve que el conocimiento sea también dinámico, de modo que se hace necesario que la educación se preocupe no solo por el conocimiento dado, sino por el conocimiento dándose, lo cual puede significar enfatizar en conocer lo que es conocer.

Esta llamada de atención pone al descubierto que no debemos insistir en elaborar verdades monolíticas, como muchos y muchas docentes, que han caído en la desidia, pretenden enseñar. Debemos entonces contextualizar el conocimiento y buscar su origen. Para desarrollar una búsqueda de conocimiento es imprescindible la investigación conjugada con la acción social que nos permita desarrollar una docencia pertinente, es decir que permita al y a la discente desarrollar una actitud crítica ante el conocimiento dado.

En otras palabras, para usar el conocimiento se debe conocer su naturaleza, así el conocimiento del conocimiento se convierte en una necesidad base para afrontar riesgos permanentes de error e ilusión, propios de la mente humana.

es necesario introducir y desarrollar en la educación el estudio de las características cerebrales, mentales y culturales del conocimiento humano, de sus procesos y 
modalidades, de las disposiciones tanto síquicas como culturales que permiten arriesgar el error o la ilusión. (Morin, 1999, s.n.)

Otro elemento que históricamente hemos relegado, han sido los afectos. Nos han enseñado que en todo proceso donde se involucre el conocimiento, hay procurar la asepsia, es decir no cruzarlo con los afectos, con la subjetividad, desterrando con ello a las y los sujetos que lo producen. Dicha escisión ha frenado en cierta medida comprender integralmente el desarrollo del conocimiento. Debemos incorporar los afectos para comprender también el desarrollo de la inteligencia, ambos son parte de la misma cuestión.

Como se dijo es importante conocer las fuentes de error; de las cuales la remembranza puede significar una de ellas. Esta puede al conocimiento pero también distorsionarlo, pues nuestra mente es la encargada de seleccionar los recuerdos y no siempre selecciona los correctos o los que mejor expresan una situación.

Asimismo las teorías, doctrinas e ideologías, están sujetas a error, y muchas veces protegen los errores e ilusiones inscritos en ellas, las cuales se resisten a la crítica de teorías adversas. Las universidades han caído en la práctica de enseñar dogmas teóricos, han cerrado los portillos a la crítica, promoviendo con esa lógica una enseñanza disciplinar, con lo cual han consolidado feudos académicos. Quebrar esa lógica significa poner el conocimiento en discusión, identificar errores e ilusiones que lo distorsionan.

Así por medio de la racionalidad se pueden combatir algunos errores e ilusiones. No obstante ella misma debe permanecer abierta a la discusión, pues debe elaborar teorías coherentes, verificando el carácter lógico de la organización teórica, de esta manera la racionalidad asume un carácter constructivista. Esa racionalidad que actúa sobre los errores e ilusiones de las creencias, doctrinas y teorías, se asume como crítica, por el contrario si la racionalidad se cierra y no dialoga con la realidad, se convierte en doctrina, en racionalización, dado que no reconoce la subjetividad, la afectividad, el amor, el arrepentimiento.

No podemos obviar que esa búsqueda de la verdad e identificación del error, tiene un fundamento en lo paradigmático, pues es desde allí que se efectúa la selección y donde se 
determina la conceptualización de las operaciones lógicas, y se designan las categorías fundamentales de la inteligibilidad (Morin, 1999).

Los principios de un conocimiento pertinente, se refieren a aquellos que son capaces de abordar los problemas globales y fundamentales para poder leer desde allí los problemas parciales y locales. Esto porque el conocimiento fragmentado de las disciplinas impide con frecuencia elaborar entramados entre las partes y las totalidades no dejando aprehender los objetos en sus contextos, complejidades y conjuntos. Para lograr esta forma de aprehender el objeto es indispensable enseñar las metodologías.

Para que un conocimiento sea pertinente se debe tomar en consideración que las informaciones suceden en un contexto que les da sentido, así la palabra necesita del texto, y éste del contexto donde se enuncia. Este contexto pertenece a una totalidad mayor que es lo global, es el planeta tierra que es multidimensional, que contiene dimensiones históricas, económicas, sociológicas, religiosas, antropológicas, entre otras palabras "es el conjunto que contiene partes diversas ligadas de manera inter-retroactiva y organizacional' (Morin, 1999, S.n.).

Esta proposición rechaza la hiperespecialización en tanto que ella fragmenta el conocimiento e impide ver lo global y a la vez difumina lo esencial, problema que se experimenta con las disciplinas que al parcelar, desunen los saberes dificultando su contextualización e interacción.

Podemos adelantar que el currículo universitario, muchas veces adolece de una visión de contexto global, por lo contrario, el mismo temor de poner en discusión los fundamentos teóricos disciplinares, lleva a establecer una pauta endógena con lo cual se cierran los cercos académicos. Así las disciplinas actuales deben mirar lo global para redefinirse en ese entramado global local que le da sentido. Las disciplinas no pueden seguir siendo continentes de conocimientos reduccionistas y especializados, cuya ruta lleva a la descontextualización.

Enseñar la naturaleza humana deviene de la consideración de que la educación, en los procesos de enseñanza, ha fragmentado esa unidad compleja que es el ser humano, 
imposibilitando su aprehensión como un ser físico, biológico, psíquico, cultural, social e histórico.

Nuevamente nos encontramos a las disciplinas actuando sobre un mismo objeto de investigación, cada una con una mirada específica que no permite la aprehensión holística. Por ejemplo, la psicología actuando por su cuenta, mientras la antropología haciendo lo propio desde su propia especificidad, pero entre ambas los conectores son débiles o no existen. Desde lo disciplinar y más allá de ello, desde la visión fragmentada de los y las profesionales, ponemos muros que no dejan mirar el patio vecino. De manera que las posibilidades de tomar conciencia de nuestra unidad como ser humano se limitan.

Debemos concienciarnos de nuestra naturaleza y del sentido que tiene ser humano, de nuestra identidad compleja común a todos los seres humanos, y ubicarnos en el espacio cósmico. Este puede representar un principio para restaurar las percepciones fragmentadas.

No basta entonces con tomar como referente una disciplina, sino por el contrario, asumir que para reconocer la unidad y la complejidad humanas se deben organizar conocimientos dispersos en otras disciplinas, de esa manera es posible comprender la unidad y la diversidad como característica inherente al ser humano. Allí podemos mirar la condición cósmica, física, terrestre, y aunque suene redundante la humana, sí y solo sí tomemos como referentes que nos desenvolvemos en espacios triangulares con vértices compuestos por el cerebro - mente - cultura; por la razón - el afecto - el impulso; el individuo - la sociedad - la especie. Estos tres triángulos no permite la escisión entre un elemento y otro, por el contrario, nos obliga a asumirnos en forma holística, es decir, la persona actuando como individuo pero perteneciente a una sociedad que a su vez pertenece a una especie. Asimismo, la persona se desenvuelve de acuerdo con la razón fusionada con los afectos y con impulsos, pero en correspondencia con la cultura de la cual forma parte.

En la medida que nos comprendamos como seres pendulando entre la unidad y la diversidad en todos los campos, en esa medida nos encontraremos con nuestras propias dimensiones, actuando en una realidad dialéctica.

El hombre de la racionalidad es también el de la afectividad, del mito y del delirio (demens). El hombre del trabajo es también el hombre del juego (ludens). El hombre empírico es también el hombre imaginario (imaginarius). El hombre de la economía es 
también el de la -consumación- (consumans). El hombre prosaico es también el de la poesía, es decir del fervor, de la participación, del amor, del éxtasis. El amor es poesía. Un amor naciente inunda el mundo de poesía, un amor que dura irriga de poesía la vida cotidiana, el fin de un amor nos devuelve la prosa. (Morin, 1999, s.n.)

No somos personas lineales, sino que a partir de las contradicciones construimos nuestras realidades, significamos el mundo de la vida. En otras palabras no somos solo racionales, sino que allí anida también la pasión, los afectos.

La identidad terrenal, por su parte alude al destino y desarrollo planetario del ser humano, lo cual plantea una realidad que no podemos obviar. En este proceso de enseñar dicha identidad, la historia toma un papel pivotal, dado que pensar en cómo se está configurando el futuro, no puede aislarse de su proceso de conformación, entonces las comunicaciones intercontinentales teñidas de opresiones y dominaciones son parte de este proceso de formación global.

Todos los seres humanos vivimos los problemas fundamentales de vida y muerte y estamos unidos en la misma comunidad de destino planetario. De ahí la importancia de aprender a "estar" en el planeta, es decir aprender a vivir, a compartir, a comunicarse, a comulgar. En estos tiempos no solo es necesario desarrollar el sentido de pertenencia a una cultura sino al planeta Tierra, para lo cual debemos apropiarnos de la conciencia antropológica, ecológica, cívica terrenal y espiritual.

Desde esta perspectiva toma relevancia, como se ha anotado, la diversidad, la unidad y el mestizaje componentes de la identidad terrenal, que significa desarrollar las poli-identidades.

La incertidumbre es uno de los aspectos que la educación no contempla como tema a enseñar, según lo afirma Morín (1999). La incertidumbre es una característica de todas las ciencias. Con esto se enseñarían estrategias para afrontar los riesgos, lo inesperado, lo incierto y modificar su desarrollo con base en la información adquirida.

El cambio de época propuesta por autores como De Souza (2001), deviene en incertidumbre, donde los valores son ambivalentes, donde existe un posible aún invisible en 
lo real, por lo que es necesario interpretar la realidad antes de reconocer donde está el realismo.

En esta misma línea, se puede decir que el conocimiento significa navegar en un mar de incertidumbres, a través de archipiélagos de certeza, (Morin, 1999). Esto nos lleva a afirmar junto con Morin que ninguna acción está segura de obrar en el sentido de su intención.

De esta forma, la respuesta a las incertidumbres de la acción está constituida por la buena elección de una decisión, por la conciencia de la complejidades inherentes a sus propias finalidades, que en el transcurso de la acción pueda modificarse en función de los riesgos, informacionales, cambios de contexto y que pueda considerar un eventual torpedeo de la acción que hubiese tomado en curso nocivo. (1999, s.n.)

La comprensión es otro de los componentes que debe tener la educación del futuro, ella es al mismo tiempo medio y fin de la comunicación humana, pero la comprensión necesita una reforma simbólica y ésta es una condición para salir de las relaciones incomprensibles. La comprensión se manifiesta de dos formas, la intelectual u objetiva y la humana intersubjetiva.

Es fundamental partir del estudio de la incompresibilidad y los efectos, para pensar y educar para la compresión, esto nos lleva a los orígenes del racismo, las xenofobias, los desprecios, en fin los prejuicios. Lograr una educación con este componente nos aproxima a una educación para la paz, que es una educación para todos.

No obstante la comprensión tiene sus propios obstáculos para entender al otro, su cosmovisión, sus ideas. Ellos giran en torno a los siguientes aspectos: el ruido que parasita en la transmisión de la información, creando el malentendido; la polisemia de una noción enunciada en un sentido e interpretada de otro; la ignorancia de los ritos y costumbres del otro; de los valores imperativos de otra cultura; imperativos éticos propios de una cultura y la imposibilidad de comprensión de una estructura mental desde otra, (Morin, 1999). Además se pueden sumar a los anteriores obstáculos el egocentrismo, el etnocentrismo y el sociocentrismo.

Finalmente la ética del género humano, debe tener su fundamento en la tríada individuo, sociedad especie (Morin, 1999), ambos unidos y autodeterminándose en la autonomía en forma dialéctica. 
Al comprender y concienciarse que el ser humano es simultáneamente individuo que es parte de una sociedad y de una especie, de la misma manera que todo desarrollo debe comprender el conjunto de las autonomías individuales, de las participaciones comunitarias y la conciencia de pertenecer a la especie humana, se desarrolla una moral.

Se trata entonces de establecer una relación de control mutuo entre la sociedad y los individuos por medio de la democracia y concebir a la humanidad como comunidad planetaria, de ahí que la educación debe contribuir a la concienciación de la construcción de una ciudadanía terrenal.

Los siete saberes indispensables para la educación del futuro anidan en su seno una forma diferente de mirar el mundo global, ponen a la educación patas arriba, la obligan a ser lúdica. Asumir dichas tesis, es quebrar las estructuras medievales sobre las se asientan muchas de las instituciones universitarias actuales. Subyace en las tesis de Morin, la mirada horizontal y vertical, extensa e intensa a la realidad, esa realidad (1999) no dada, dinámica y compleja.

No bastan las disciplinas, no bastan las experticias, no bastan los saberes encarcelados, no bastan los centrismos, es necesario echar abajo esas estructuras para erigir otras que contengan aquello que nos asombre, lo inédito. Esto es lo que debe presiona y dinamizar una reestructuración del currículo y con ella la administración.

La educación universitaria, pensada de esa forma nos lleva a considerar que no podemos plegarnos a una investigación debilitada por haberse desarrollado desde un solo paradigma. Debemos introducir e introducirnos en otras propuestas investigativas con el fin de tener una mayor aproximación a esa realidad y simultáneamente alejarnos del error y de la ilusión.

De la misma manera reconocer las identidades, tanto locales como terrenales, lleva a pensar más en la esencia del ser humano, y exige de la educación revalorar los saberes y flexibilizar los cercos para incorporar otros contenidos hasta hoy olvidados y silenciados. Asimismo se debe pensar más allá de las disciplinas formales para crear nuevas opciones interdisciplinarias de formación, esto permite podar la experticia como categoría académica y ofrecer saberes que sean accesibles a todas las personas, de acuerdo con su interés profesional, laboral y académico. 
Finalmente la comprensión y la ética humanas, ponen sobre el tapete la necesidad de dar cabida a esas voces silenciadas, excluidas de los procesos educativos.

Las reflexiones anteriores no agotan la discusión teórica acerca de la Universidad, ellas corresponden a una selección de ideas, conceptos, referentes teóricos que sirvieron para sustentar e interpretar un problema.

\section{ABRIR PUERTAS PARA RECONSTRUIR LA UNIVERSIDAD}

Las personas artífices de la educación universitaria debemos asumir con claridad el compromiso que adquirimos cuando aceptamos estar en una institución formadora de profesionales. Es en ese sentido el norte será la liberación de las ataduras de la alienación en la cual hemos estado sometidos. En otras palabras, debemos aportar en la construcción de una sociedad de la comunicación para desterrar la sociedad de la información; con ella damos cabida a los saberes necesarios discutidos en el segmento anterior.

Cuando hablamos de sociedad de la información, nos referimos a aquellas sociedades configuradas con base en el agrupamiento de conglomerados humanos con una jerarquía claramente definida, en donde unos pocos toman las decisiones por los muchos que la habitan. En este tipo de sociedad podemos enlistar a las teocracias, monarquías, imperios, dictaduras, incluyendo las democracias occidentales. La sociedad de la comunicación, basada en la sociedad abierta, es la que está habitada por ciudadanos libres y participativos, por individuos críticos y reflexivos, que requiere del diálogo entre iguales, del acuerdo entre los distintos, pero tolerantes para un gobierno horizontal. (Galindo, 1998)

Si tomamos en consideración que la columna vertebral de una institución educativa es el lugar, donde se reflejan la historia social y cultural de un pueblo, su historia educativa, su currículo, sus presentes con sus cosmovisiones, entonces se puede comprender el currículo como una instancia donde se fraguan los saberes que por mediaciones varias, componen los procesos de enseñanza y de aprendizaje, sometidos a estructuras propias de la institución y guiadas por relaciones sociales que son gestadas en su interior por las personas que lo ejecutan.

Para asegurarnos una universidad pertinente, debemos construir un currículo democrático, que desde la institución, abra las posibilidades para que toda persona habitante de nuestro 
país, tenga acceso en igualdad de condiciones, sin que medie otro criterio que los requisitos académicos para su ingreso, y que tengan la oportunidad de terminar con éxito una formación que los faculte para incorporarse, con una mente crítica, a un puesto de trabajo y desenvolverse adecuadamente en ámbitos sociales y culturales diversos.

Esto irremediablemente nos coloca en la exigencia de crear planes de estudio flexibles, basados en problemas propios, de nuestra región articulada al planeta tierra, para ser resueltos desde vertientes múltiples, abordados en equipo y en forma interdisciplinaria, para crear diálogos interdisciplinares y transdisciplinarios orientados en la resolución de problemas específicos. En el estudio de dichos problemas nos someteríamos a los procesos de enseñanza y aprendizaje, en los cuales adquiriríamos nuestras competencias laborales y sociales desarrollando así la capacidad de asombro.

La flexibilidad curricular requiere destronar la visión disciplinar, dominante hasta ahora, para dar cabida a un modelo educativo donde las personas puedan entrar y salir de los espacios áulicos y virtuales, según se presenten las necesidades sociales y laborales. Así una persona puede ingresar y formarse para atender una exigencia laboral, cultural o social determinada, pero cuando esa formación no sea suficiente, pueda reingresar para continuar su formación en otro campo o en campos afines. Es posible que la formación profesional culmine cuando el o la profesional haya adquirido las competencias necesarias para desenvolverse en un espacio laboral y social amplio y seguro.

La flexibilidad es una cara de la moneda, la otra es el dinamismo, característica que no siempre está presente en los modelos universitarios. El dinamismo está asociado a las rutas para conseguir las metas, lo cual se impone la necesidad de que estas sean más directas y libres de obstáculos administrativos. Necesitamos por tanto un concepto de gestión de la administración que nos faculte para proceder con base en la confianza y la comunicación y no en el control, que permita realizar cambios a favor de un currículo flexible para procurar una universidad pertinente y eficiente.

No debemos omitir que tanto flexibilidad como dinamismo poseen un sustento dialógico. Esto es posible si las personas involucradas en la elaboración, ejecución y consumo curricular, participamos en forma responsable y con una ética humanista, colocados en el espacio del 
diálogo, no solo con pares docentes, sino con las teorías y las realidades presencial y virtual.

Pensar un currículo pertinente con el momento histórico actual, nos empuja a incorporar las diferentes realidades, como la virtualidad y la presencialidad, dos ámbitos que no debemos obviar, pues su atención somete a evaluación los conocimientos con que llegamos a enfrentar los procesos de enseñanza y aprendizaje. Por lo tanto una permanente reflexión nos abre los caminos para renovar los conocimientos en forma continua, con el fin de establecer ámbitos dialógicos donde las personas comuniquen y se comuniquen alrededor de un problema, de manera científica, redundando en el planteamiento de nuevas competencias acordes con nuestra realidad.

Pensar el currículo universitario desde esta óptica, nos lleva irremediablemente a repensar la mediación pedagógica. Debemos buscar nuevas alternativas para recomponer los procesos de enseñanza y aprendizaje, que nos liberen de un espacio áulico y de recursos técnicos limitados. Más allá de las posibilidades que nos ofrecen las tecnologías, debemos reactivar nuestra creatividad en el uso de los recursos.

La indisolubilidad de las tres áreas sustantivas, la docencia, la investigación y la acción social, más la administrativa, sería la plataforma donde se podría implementar un currículo como el dibujado en las líneas anteriores. Esto no resta que la docencia siga vertebrando el quehacer universitario, el deber ser de la institución, ella debe responder a las necesidades que la flexibilidad curricular demande. Por consiguiente, la organización de la administración facilitaría la organización para permitir que el cuerpo docente pueda atender las necesidades interdisciplinares que demanden los problemas que se abordan. De modo que un profesor o profesora no tenga un lugar de pertenencia exclusivo, sino por el contrario que existan canales que les permitan transitar de un área académica a otra.

Asimismo, el compromiso de la docencia con las realidades que experimentamos diariamente es inminente y debe dar cuenta de nuestra posición identitaria en relación con el planeta Tierra. Es una forma de atender los problemas responsablemente desde lo académico y ético. 
Actuando en una relación dialógica y codependiente, estarán la investigación y la acción social, ambas no solo estarían en diálogo con la vida académica sino también con las realidades en las que nos desenvolvemos, de esa manera podemos asegurarnos de que los problemas que sustentan las formaciones profesionales nos pertenecen. Las tres áreas al pertenecer a la estructura curricular estarían actuando allí donde se desarrolla cualquier actividad curricular. Es también de esa manera también que nos asomaríamos a lo inédito e incierto para construir horizontes de esperanza.

La docencia, la investigación y la acción social actuando indisolublemente, permitirían aprehender un conocimiento pertinente, capaz de facilitar el abordaje de los problemas globales que a su vez, permitirían leer los locales.

La estructura universitaria es también susceptible de cambios, para que dé soporte a una propuesta curricular que trascienda la organización heredada de la modernidad, organizada por disciplinas, debe reconfigurarse de modo tal que permita establecer rutas de decisión ágiles y flexibles, con procedimientos más directos y acotados. También el diálogo entre las instancias encargadas de la gestión y las que implementan acciones académicas caracterizaría dicha propuesta. La estructura necesariamente debe reflejar aquello que le es propio al currículo, como la flexibilidad, el dialogismo, el dinamismo, entre otros, con el fin de que dar apoyo al accionar académico.

La gestión universitaria se catapultaría y convocaría a todas las personas involucradas en el currículo, a participar activamente en el logro de la excelencia académica. Este objetivoesperanza configuraría el deber ser de toda actividad que se realice dentro de los ámbitos universitarios. La gestión procuraría la participación en todos los niveles, el diálogo entonces sería su leitmotiv.

Así la excelencia académica se convierte en el proceso y producto donde convergen todas las acciones curriculares que formarían a las personas en correspondencia con las necesidades sociales que emergen de las realidades presenciales y virtuales y las exigencias de los sectores empleadores. Allí las personas que entren y salgan de los espacios universitarios tendrían los conocimientos teórico-prácticos pertinentes para abordar las problemáticas que se presenten, en sus cotidianidades locales, desde un conocimiento global. 
Podemos insistir que el personal que decida ser artífice y partícipe del currículo universitario, debe tener clara conciencia de su lugar en la región y en el globo terráqueo, conciencia que afinaría por otro lado su noción antropológica y su responsabilidad con la diversidad, interculturalidad, diferencia, respeto y tolerancia. Condición necesaria para poderse autodefinir como persona académica.

Este escenario, en donde la investigación, la acción social y la docencia están entrelazadas, es factible promover el desarrollo del conocimiento, y con ello construir ilusiones y desterrar los errores, realimentando los saberes que se enseñan y las didácticas. Este nuevo conocimiento es susceptible de articularlo a las realidades globales para comprender lo local. Asimismo si las tres áreas actúan en conjunto, necesariamente nos lleva a comprender al ser humano holísticamente, como parte de una cultura con sus propios afectos y esperanzas. 


\section{REFERENCIAS}

Araya, Carlos. (2003). Crecimiento, democratización y diversificación de la Educación Superior en Costa Rica (1970-1994). En: Salazar, J.M. Historia de la educación costarricense. Costa Rica: Editorial Universidad Estatal a Distancia, Editorial Universidad de Costa Rica.

Benedito, Vicenc, Ferrer, Virginia, y Ferreres, Vicent. (1995). La formación universitaria a debate. España: Publicacions de la Universitat de Barcelona.

Bourdieu, Pierre. y Wacquant Loïc J.D. (1995). Respuestas por una antropología reflexiva. México. Editorial Grijalbo S.A.

Camacho, Daniel. (1990). La inacabada lucha pro-académica del III Congreso Universitario. Revista de Ciencias Sociales (49-50). Editorial de la Universidad de Costa Rica.

De Alba, Alicia (Coord.). (1996). Teoría y Educación. En torno al carácter científico de la Educación. México: Universidad Nacional Autónoma de México.

De Souza, José. (2001). La dimensión institucional del desarrollo sostenible. De las "reglas de la vulnerabilidad" a las "premisas de la sostenibilidad" en el contexto del cambio de época. Costa Rica: Mimeo.

Didrickson, Axel. (2000). La universidad del futuro. México: Centro de Estudios sobre la Universidad. Plaza y Valdés Editores. Universidad Nacional Autónoma de México.

(2002). Tendencias en la educación superior en el Mundo. En: Comboni, Juárez y París (coord), ¿Hacia dónde va la Universidad Pública? México: Universidad Autónoma Metropolitana, Unidad Xochimilco.

Follari, Roberto. (1994). Los retos del siglo XXI ante el Estado evaluador. En: Puiggrós, A. y C. Krotsch. Universidad y evaluación. Estado del debate. Argentina: Rei Argentina S.A. y Aique Grupo Editor S.A.

Foucault, Michael. (1992). Microfísica del poder. España: Las ediciones de La Piqueta.

Gacel-Ávila, Jocelyne. (2003). La internacionalización de la educación superior. Paradigma para la ciudadanía global. México: Universidad de Guadalajara.

García-Canclini; Néstor. (1995). Ideología, cultura y poder. Argentina: Oficina de publicaciones del C.B.C. Universidad de Buenos Aires.

González, Yamilet. (2003). Educación Diversificada y humanista para una democracia integral (1950-1970). En: Salazar, J.M. (ed.): Historia de la educación costarricense. Costa Rica: Editorial Universidad Estatal a Distancia, Editorial Universidad de Costa Rica.

Gurdián, Alicia. (1994a). El impacto de los cambios globales en el curriculum universitario. Costa Rica. Seminario Universidad desarrollo. Universidad de Costa Rica. 
(1994b). El curriculum universitario y los desafíos del futuro. En: Gurdián, A. (Comp.) Proyecto de universidad para el siglo XXI. Costa Rica: Oficina de publicaciones de la Universidad de Costa Rica.

. (2000). Dinámica de la Educación Superior en Costa Rica: Desafíos y tendencias (1996-1999). Mimeo. Octubre de 2000.

Herrera, Rosalila y Rodríguez; María Elena. (1994). Universidad y Reformismo en Costa Rica. Costa Rica: Editorial de la Universidad de Costa Rica.

Juárez José Manuel y Comboni, Sonia. (2002). Prólogo. En: Comboni, Juárez y París (coord) ¿Hacia dónde va la Universidad Pública? México: Universidad Autónoma Metropolitana, Unidad Xochimilco.

López, Olimpia. (2004). Universidad del siglo XXI. San José: Editorial Guayacán.

Morin, Edgar. (1999). Los siete saberes necesarios a la educación del futuro. París: UNESCO.

(2002). Los siete saberes necesarios a la educación del futuro. Buenos Aires: Nueva Visión.

(2001). La cabeza bien puesta. Repensar la reforma. Reformar el pensamiento. Buenos Aires: Nueva Visión.

París, María Dolores. (2202) Introducción. En: Comboni, Juárez y París (coord) ¿Hacia dónde va la Universidad Pública? México: Universidad Autónoma Metropolitana, Unidad Xochimilco.

Pérez, Augusto. (1985). Universidad, política y sociedad. Argentina: EUDEBA S.E.M. Buenos Aires.

. (1998). Políticas del conocimiento: educación superior y universidad. Argentina: Editorial Biblos.

Pérez, Angel. (1999). La cultura escolar en la sociedad neoliberal. Madrid: Ediciones Morata, S. L.

Quesada, Rolando. (2000). Cultura, poder y curriculum, todos en el mismo crisol. Educación. Revista de la Universidad de Costa Ric, 24 (2). Editorial de la Universidad de Costa Rica.

(2001). Aproximaciones para llegar al fondo del pozo. Evaluación curricular en los "cercos académicos". Revista de Ciencias Sociales, 93-94 (II-III). Editorial de la Universidad de Costa Rica.

. (2001). Reforma curricular: rito y acto de fe. Revista de Ciencias Sociales, 94 (IV). Editorial de la Universidad de Costa Rica.

Ruiz, Ángel. (2001a). La Educación Superior en Costa Rica. Costa Rica: Comisión Nacional de Rectores. Editorial de la Universidad de Costa Rica. 
(2001b). El destino de Costa Rica y la Educación Superior. Costa Rica: Comisión Nacional de Rectores. Editorial de la Universidad de Costa Rica.

. (2001c). El siglo XXI y el papel de la Universidad. Costa Rica: Comisión Nacional de Rectores. Editorial de la Universidad de Costa Rica.

Tedesco, Juan Carlos. (2000). Universidad y sociedad del conocimiento. En Gestión, evaluación y acreditación de instituciones de Educación Superior. Seminario regional (s.n.p.). Buenos Aires: IESALC. FLACSO-Argentina. OEI. IIEP.

Thompson, John. (1993). Ideología y cultura moderna. México: Universidad Autónoma Metropolitana.

Universidad de Costa Rica. (1979). Estatuto Orgánico. San José: Oficina de Publicaciones de la U.C.R.

Publicaciones de la U.C.R.

(1990). Estatuto Orgánico. San José: Oficina de

Zemelman, Hugo. (1992a). Los horizontes de la razón. I Dialéctica y apropiación del presente. España: Editorial Antropos.

(1992b). Los horizontes de la razón. II Historia y necesidad de utopía. España: Editorial Antropos. 